\title{
Formulation Development and Evaluation of Duloxetine Hydrochloride Multi-Particulate Delayed-Release Capsules
}

\author{
SR Suseem ${ }^{1 *}$, Dhanish Joseph ${ }^{2}$ \\ 'Department of Chemistry, School of Advanced Sciences, VIT, Vellore, Tamil Nadu, INDIA. \\ 2Department of Pharmaceutics, Nirmala College of Pharmacy, Muvattupuzha, Ernakulam, Kerala, INDIA.
}

\begin{abstract}
Background: Multi-particulate drug delivery systems are mainly oral dosage forms consisting of a multiplicity of small discrete units, each exhibiting some desired characteristics. Duloxetine hydrochloride is acid-labile thus it is formulated as gastro-resistant pellets. Objective: The work aims to develop Delayed-release oral capsules comprising Duloxetine $\mathrm{Hcl}$ pellets which is similar in dissolution profile and bioavailability, there by establishing bio equivalence to that of the reference product-Cymbalta ${ }^{8}$. Methods: The pellets are formulated in a fluidised bed processor, by Wurster process. The finished pellet consists of four different layers, coated over the sugar spheres. The first layer is the drug layer, followed by a barrier layer to separate enteric layer and drug, finally a top layer that acts as a moisture barrier. The pharmaceutical equivalence and stability of finished product to that of the standard was the primary objective during the development of each layer. Thus, in all stages of development, the dissolution and stability were closely monitored and the excipients were optimized based omit. Results: Poor process efficiency, multi-pellet formation and low dissolution of the drug layer are resolved by the addition of HPMC,
\end{abstract}

talc and corn starch respectively. The moisture permeability across the barrier layer was arrested by Opadry ${ }^{\circledR}$ AMB white. 25-30\%. 25\% coating thickness with Eudragit L-30-D55 provides acid resistance and timely drug release. Finally, a $5 \%$ coating with Opadry ${ }^{\circledR}$ AMB again provides complete moisture protection. Conclusion: Developed pharmaceutically equivalent and stable dosage form of Duloxetine Hydrochloride

Key words: Duloxetine Hcl, Multi-particulate, Delayed release, Eudragit, Pellets, Wurster coating,

Correspondence

Dr. SR Suseem,

Department of Chemistry, School of Advanced Sciences, VIT, Vellore-632014, Tamil Nadu, INDIA.

Phone: +919846984399

Email: srsuseem@vit.ac.in;

ORCID: http://orcid.org/0000-0002-3729-5303

DOI: 10.5530/ijpi.2020.2.30

\section{INTRODUCTION}

Major depressive disorder (MDD) is a common psychiatric disease. It is one of the leading causes of disability. ${ }^{1}$ significant morbidity, mortality and suffering for patients and their families. ${ }^{2} \mathrm{MDD}$ is characterized by a persistent feeling of sadness low self-esteem, loss of interest in normally enjoyable activities, low energy and pain without a clear cause. The mood can sometimes appear as irritability. The etiology of MDD is multi factorial. ${ }^{3}$ Fortunately, MDD is well symptomatic and easily understood in the medical community. Among the various methods to treat MDD, Duloxetine of Serotonin and noradrenaline reuptake inhibitors (SNRIs) class is a newer molecule. It is neither sedative, nor anticholinergic, antihistaminic and an a blocker. ${ }^{4}$ US FDA approved Duloxetine for the treatment of MDD, diabetic peripheral neuropathic pain and generalized anxiety disorder. The European Medicinal Agency (EMEA) approved it for the treatment of moderate to severe stress urinary incontinence. ${ }^{5}$

Duloxetine exists in its salt form as duloxetine hydrochloride (DXL) with Molecular Formula: $\mathrm{C}_{18} \mathrm{H}_{19} \mathrm{NOS}$. HCl. It is well absorbed and has a bioavailability of $80 \%$. However, the DXL is least stable with acidic $\mathrm{pH}$ of gastric fluid. $60 \%$ of DXL gets degraded in $30 \mathrm{~min}$ of contact with acid. Some degradation product of duloxetine includes " $\alpha$ - naphthol", "4 - naphthol Duloxetine", "3 -acetyl Duloxetine" Figure 1. Thus, to prevent acid degradation it must be developed as delayed-release formulation.

Current work aims to develop the DXL as a multi particulate delayedrelease capsule. Multi-particulate drug delivery systems (MPDDS) are oral dosage forms consisting of a multiplicity of small discrete units, each exhibiting some desired characteristics. In these systems, the dosage of the drug substances is divided into the number of subunits, typically consisting of thousands of spherical particles with a diameter of $0.05-2.00 \mathrm{~mm} .{ }^{6}$ The purpose of designing MPDDS is to develop a reliable formulation that has all the advantages of a single unit formulations and yet devoid of the danger of alteration in drug release profile and formulation behavior due to unit to unit variation, change in gastroluminal $\mathrm{pH}$ and enzyme population. Pellets are a type of MPDDS were drug profiles are created by layering an active drug onto a neutral core such as sugar spheres, crystals or granules Figure 2, followed by the application of a rate-controlling or a functional membrane.

\section{MATERIALS AND METHODS}

\section{Materials}

Sugar spheres (Suglets ${ }^{\oplus}$ from Colorcon 250-255 $\mu \mathrm{m}$ ) HPMC E 5 methocel ${ }^{\mathrm{TM}}$ LV Povidone K29/32 (Plasdone ${ }^{\mathrm{TM}}$ ) EUDRAGIT L-100-55, EUDRAGIT L-30-D-55 (Evonik) Opadry AMB white (colorcon ${ }^{\circledR}$ ) received as gift sample from Orchid Health Care, Chennai. All other chemicals and reagents used were of analytical grade.

\section{Methods}

\section{Wurster fluid bed coating}

FBP (Fluidized bed processor) from Glatt GPCG-1, Germany. Bottom spray, 'C' plate, ASTM \#40 mesh was used for fluid bed coating. The core material (sugar spheres) of 710-850 $\mu \mathrm{m}$ size after sieving through

This is an open access article distributed under the terms of the Creative Commons Attribution-NonCommercial-ShareAlike 4.0 License, which allows others to remix, tweak, and build upon the work non-commercially, as long as the author is credited and the new creations are licensed under the identical terms. 


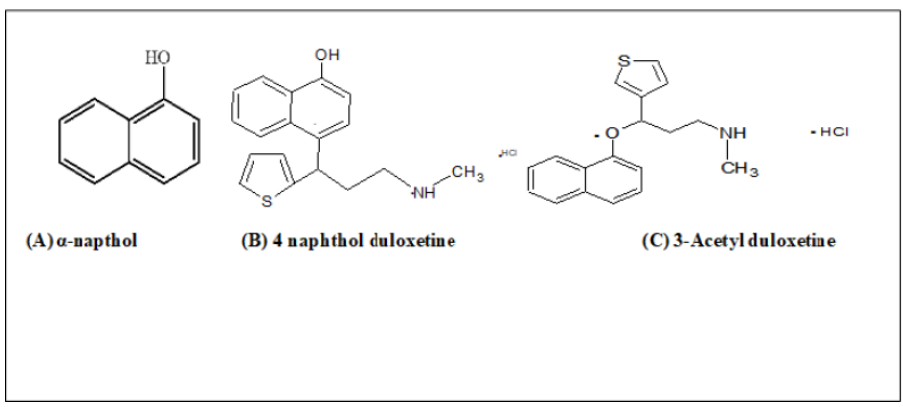

Figure 1: Degradation products of duloxetine hydrochloride (A), a- naphthol. (B) 4 - naphthol Duloxetine, (C) 3 -acetyl Duloxetine.

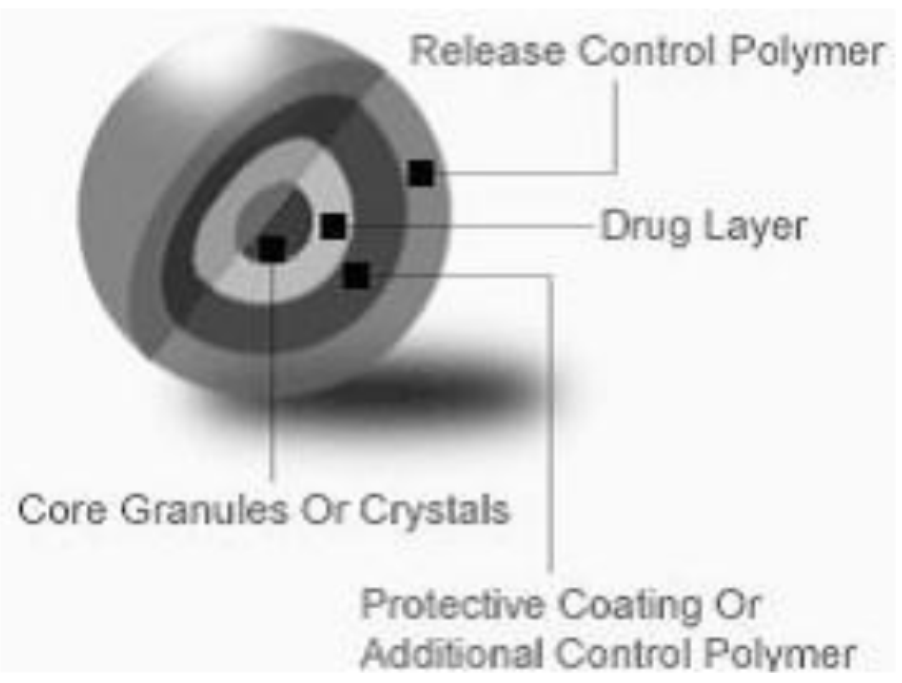

Figure 2: Various layers of Multi-particulate drug delivery systems.

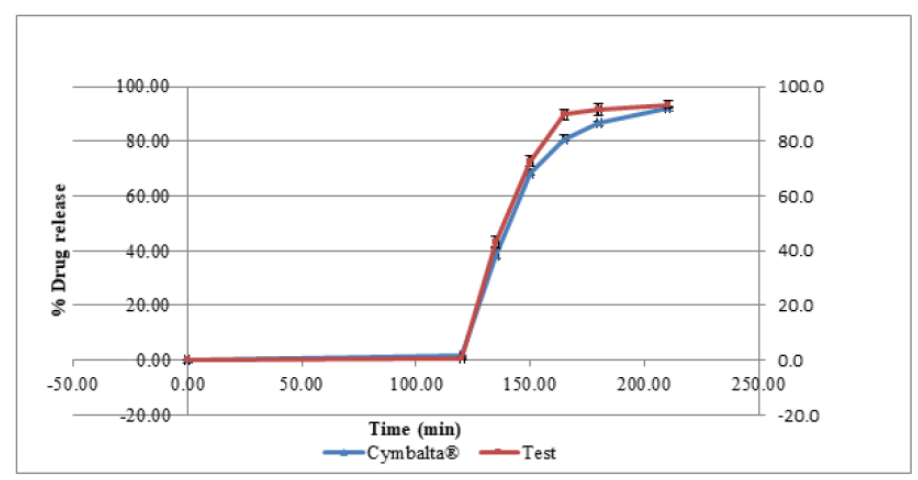

Figure 3: Dissolution Data comparison with marketed formulation.

ASTM\#20-25 mesh were loaded into the FBP. The sugar spheres were heated up to a bed temperature of $30-40^{\circ} \mathrm{C}$. The coating solutions for each layer were sprayed over the sugar spheres through $1.00 \mathrm{~mm}$ nozzlein synchronization $\mathrm{ON}$ mode. The process parameters for different layers are given in Table 1. After the coating of each layer, the pellets were cured for $12-14$ hrs at $40-45^{\circ} \mathrm{C}$.

\section{Development of DXL enteric-coated Pellets}

The developments of DXL enteric-coated Pellets under various stages. Stage I: Drug layering over the sugar spheres. Stage II: Barrier coating over the drug layer to prevent drug and enteric polymer interaction .
Stage III: Enteric coating over the barrier coated pellets and Stage IV: Top coating over the enteric-coated pellets to avoid the moisture permeability, to provide a better finishing and for lubrication. At each stage of its development, the pellets were evaluated for its quality and all the supportive factors responsible were optimized.

\section{Stage 1: Development of drug-loaded pellets}

The sugar spheres are coated with DXL in FBP. DXL is made into a $20 \%$ aqueous dispersion by incorporating binder (HPMCE5 or PVPK30), anti-static agent (talc) and disintegrant (cornstarch). The type and amount of binder required for coating are optimized by different trials, based on process efficiency, assay, dissolution, friability and disintegration. The amount of anti-static agent required to produce the least amount of multi pellets and the amount of disintegrant required to produce the immediate dissolution is also optimized in stage I. For The preparation of DXL aqueous dispersion, the binder was dispersed in the required quantity of water, corn starch was added and stirred well followed by addition of talc. Finally, DXL powder was added into the above solution under stirring. Homogenized the dispersion for $30 \mathrm{~min}$ to make it uniform. The above dispersion was passed through ASTM \# $40.360 \mathrm{~g}$ of sugar spheres for 3000 capsules $(120 \mathrm{mg} / \mathrm{capsule})$ were loaded in FBP and coated with the above-prepared drug solution. The process parameters for drug layering is mentioned in Table 1.

\section{Stage II: Development of barrier coated pellets}

The suitability of excipient as a barrier coating material is evaluated by giving a $10 \%$ build-up of barrier coating over the sugar spheres followed $20 \%$ enteric coating with Eudragit L -100-55 over the barrier coated pellets. Different pharmaceutical excipients were tested for their suitability as a barrier material. A $10 \%$ aqueous dispersion of all the excipients were prepared.

\section{Preparation of coating dispersion}

Dispersion 1: For sucrose barrier combination of sucrose, talc, HPMC $(45: 25: 30),{ }^{8}$ were selected. Sucrose was initially dissolved in water followed by HPMC was dissolved in it finally talc was added and homogenized for $30 \mathrm{~min}$.

Dispersion 2: For HPMC barrier, combinations of HPMC, talc $(75: 25)^{9}$ were selected. HPMC 5 Cps was dissolved in water followed by talc was added and homogenized for $30 \mathrm{~min}$.

Dispersion 3: For PVP barrier, the combination of PVP K 30, talc (75:25), ${ }^{10}$ were selected the PVP K29/30 dissolved in water followed by talc was added and homogenized for $30 \mathrm{~min}$.

Dispersion 4: For Opadry coating, the desired quantity of Opadry ${ }^{\circ} \mathrm{AMB}$ (O-AMB) dispersed in water and homogenized for $30 \mathrm{~min}$.

The above dispersion was passed through ASTM \# 40 before coating.

\section{Barrier coating process}

475.8g of Drug loaded pellets for a batch size of 2000 capsules (237.9 $\mathrm{mg} /$ capsule) were loaded in FBP and coated with dispersion 1 based on the process parameters given in Table 1. The process was repeated for remaining dispersion also. The efficiency of barrier material was evaluated based on friability and Aspect Ratio ${ }^{11}$ of barrier coated pellets and percentage moisture pickup by enteric-coated pellets on direct exposure stability study at $40 \pm 2^{\circ} \mathrm{C} / 75 \pm 5 \% \mathrm{RH}$ for three days. The moisture content was determined by Karl Fisher titration. For friability test, $10 \mathrm{~g}$ of pellets along with $10 \mathrm{~g}$ of glass beads together tested at $25 \mathrm{rpm}$ for 10 min using Rochefriabilator. The friability results were reported as the percentage of the pellets that passed through the 20 mesh sieve size, after the test. ${ }^{12}$ 
Table 1: Process Parameters for developing MPDDS in FBP.

\begin{tabular}{|c|c|c|c|c|c|}
\hline $\begin{array}{c}\text { Process } \\
\text { parameters }\end{array}$ & Drug layer & Barrier layer & $\begin{array}{c}\text { Enteric } \\
\text { layer-100-55 }\end{array}$ & $\begin{array}{c}\text { Enteric layer } \\
\text { L-30-D-55 }\end{array}$ & Top layer \\
\hline Atomisation pressure & $1.5 \mathrm{bar}$ & 1.5 bar & $1.3 \mathrm{bar}$ & $1.3 \mathrm{bar}$ & $1.3 \mathrm{bar}$ \\
\hline Inlet temperature & $45-50^{\circ} \mathrm{C}$ & $50-55^{\circ} \mathrm{C}$ & $30-35^{\circ} \mathrm{C}$ & $30-35^{\circ} \mathrm{C}$ & $30-35^{\circ} \mathrm{C}$ \\
\hline Bed temperature & $28-30^{\circ} \mathrm{C}$ & $36-38^{\circ} \mathrm{C}$ & $28-30^{\circ} \mathrm{C}$ & $28-30^{\circ} \mathrm{C}$ & $26-28^{\circ} \mathrm{C}$ \\
\hline Spray rate & 5-15 rpm & 5-13 rpm & 5-10 rpm & 5-10 rpm & 5-10 rpm \\
\hline Fluidisation & 80-85 CFM & 80-85 CFM & 80-85 CFM & 45-60 CFM & 80-85 CFM \\
\hline
\end{tabular}

Table 2: Optimized formula for the development of DXL enteric-coated pellets.

\begin{tabular}{|c|c|c|c|c|}
\hline \multirow{2}{*}{$\begin{array}{c}\text { Sl.no } \\
1\end{array}$} & \multirow{2}{*}{$\begin{array}{l}\text { Ingredients } \\
\text { Sugar spheres }\end{array}$} & \multicolumn{2}{|c|}{$\begin{array}{c}\text { Mg/unit Quantity/ } \\
\text { batch(gm) }\end{array}$} & \multirow{2}{*}{$\begin{array}{c}\begin{array}{c}\text { Actual } \\
\text { quantity } \\
\text { (gm) }\end{array} \\
360\end{array}$} \\
\hline & & 120 & 360 & \\
\hline 2 & $\begin{array}{c}\text { Duloxetine } \\
\text { hydrochloride }\end{array}$ & 67.3 & 201.9 & 207.95 \\
\hline 3 & Hpmc 5 cps & 20.6 & 61.8 & 61.8 \\
\hline 4 & Talc & 15 & 45 & 46.35 \\
\hline 5 & Corn starch & 15 & 45 & 46.35 \\
\hline \multirow[t]{2}{*}{6} & Purified water & Qs & Qs & 1449.8 \\
\hline & Total & & 237.9 & \\
\hline \multicolumn{5}{|c|}{ Barrier coating $10 \%$ (2000 units) } \\
\hline & Drug loaded pellets & 237.9 & 475.8 & 475.8 \\
\hline 7 & Opadry amb white & 23.79 & 47.58 & 57.06 \\
\hline \multirow[t]{2}{*}{8} & Purified water & Qs & Qs & 513.86 \\
\hline & Total & & 261.69 & \\
\hline \multicolumn{5}{|c|}{ Enteric coating 25\% (2000 units) } \\
\hline & Barrier coated pellets & 261.69 & 523.38 & 523.38 \\
\hline 9 & Eudragit L -30-D-55 & 54.51 & 109.03 & 130.84 \\
\hline 10 & TEC & 5.45 & 10.9 & 13.08 \\
\hline 11 & Micronised talc & 5.45 & 10.9 & 13.08 \\
\hline \multirow[t]{2}{*}{12} & Purified water & Qs & Qs & 522.76 \\
\hline & Total & & 327.1 & \\
\hline \multicolumn{5}{|c|}{ Top coating $5 \%$ ( 2000 units) } \\
\hline & Enteric coated pellets & 327.1 & 654.2 & 654.2 \\
\hline 13 & Opadry ${ }^{*}$ AMB white & 16.35 & 32.71 & 39.25 \\
\hline \multirow[t]{2}{*}{14} & Purified water & Qs & Qs & 352.37 \\
\hline & Total & & 343.45 & \\
\hline
\end{tabular}

\section{Stage III: Development of enteric-coated pellets}

The Enteric layer is the most functional coating in development of DXL pellets. Eudragit L-100-55, L-30- D-55, were used as enteric polymers, Triacetin $^{13}$ Triethyl citrate (TEC) $)^{14}$ as a plasticizer for these polymers respectively and micronized talc $(10 \%)$ as an antistatic agent. The plasticizer level (5\%, 10\%, 15\%) and polymer build-up (15\%, 20\%, $25 \%)$ were optimised in the preliminary trials. Isopropyl alcohol, Methylene chloride and Purified water (55:25:20) as a solvent for EudragitL-100-55. The enteric coating solution was prepared by dissolving Eudragit L-100-55 dissolved in Isopropyl alcohol. The plasticizer and talc were added and stirred for 30min under closed condition. The solid content was maintained as $10 \%$. Eudragit L -30-D-55 aqueous dispersion was mixed with plasticizer and stirred for $30 \mathrm{~min}$. The dispersion passed through ASTM\#40 before coating. $523.38 \mathrm{~g}$ of barrier coated pellets $(261.69 \mathrm{mg} / \mathrm{capsules})$ for a batch size of 2000 capsules were loaded in FBP and coated with aboveprepared dispersion.

\section{Stage IV: Development of top layer}

The to player of pellets was made with (O-AMB).10\%O-AMB dispersion was prepared in purified water and stirred for $45 \mathrm{~min}$. $654.2 \mathrm{gm}$ of entericcoated pellets ( $327.11 \mathrm{mg} /$ capsule) for a batch size of 2000 capsules were loaded in FBP and coated with above prepared aqueous dispersion.

\section{Validation batch}

The optimized formula in varies stages of development of DXL entericcoated pellets are given in Table 2 . The formula is further validated and the results were compared with the marketed preparation. The resultant pellets were tested for drug content by UV method at $288 \mathrm{~nm}$. Dissolution was carried out in $0.1 \mathrm{~N} \mathrm{HCl}$ for 2 hrs followed by $\mathrm{pH} 6.8$ Phosphate buffer for $1.5 \mathrm{hrs}$. Gastric challenge test was carried out in USP I, $100 \mathrm{rpm}$, $1000 \mathrm{ml} 0.1 \mathrm{~N} \mathrm{HCl}$ for 2 hours and the pellets were assayed for drug content. Direct exposure study at $40 \pm 2^{\circ} \mathrm{C} / 75 \pm 5 \% \mathrm{RH}$ for 15 days followed by moisture evaluation by Karl Fisher titration. The formulation was compared with the standard using similarity factor and 2 way ANOVA.

\section{RESULTS}

\section{Stage 1: Drug loaded pellets}

The drug-loaded pellets were developed and the supportive factors were optimized. The optimum binder was determined based on the process efficiency on coating, assay and dissolution. Friability of pellets and static Disintegration time, are the secondary parameters depend on type and concentration of binder. The Anti-static agent (talc) reduces the static energy FBP and prevents the formation of multi pellets. The amount of talc is optimized based on the amount of multi pellets formed and dissolution. An addition of $2 \%$ talc reduces the multi pellet formation without affecting dissolution. Incorporation of more quantity of talc can reduce dissolution.

\section{Optimization of binder}

Table 3 shows the effect of binder on different evaluation test for its optimization. The rank obtained for each evaluation parameter determines the amount of binder required to develop the drug layer over the core pellets. The binder that yields the highest Drug loading Efficiency, drug content, Dissolution, the lowest Friability and Disintegration time is the most suitable for the drug layer. Higher the process efficiency higher the drug content. The results of all evaluation parameters for the development of the drug layer are tested for statistical significance by two-way ANOVA using sigma plot 14.0.

20.6mg of HPMC significantly increased the process efficiency $(P<0.050)$, compared with other batches of HPMC and PVP K30. Compared with $20 \mathrm{mg}$ of PVP K 30, $20.6 \mathrm{mg}$ of HPMC significantly reduced the friability 
Table 3: Effect of binder on Efficiency, Friability, Disintegration, Assay and Dissolution.

\begin{tabular}{ccccc} 
Formulation Variable & Process Efficiency \% & Friability \% & $\begin{array}{c}\text { Disintegration time } \\
\text { (min) }\end{array}$ & $\begin{array}{c}\text { Dissolution at } \\
90^{\text {th }} \text { min }(\%)\end{array}$ \\
\hline HPMC 10mg/unit & $80.66 \pm 5.132$ & $1.13 \pm 3.06$ & $1.0 \pm .2$ & $82.367 \pm 2.511$ \\
HPMC 20mg/unit & $90.667 \pm 3.055$ & $0.717 \pm .189^{* *}$ & $1.8 \pm .20$ & $89.00 \pm 2.62$ \\
Povidone K29/30 10mg/unit & $76 \pm 5.292$ & $1.567 \pm 0.153$ & $1.233 \pm .208$ & $88.667 \pm 3.21$ \\
Povidone K29/30 20mg/unit & $83 \pm 2.646$ & $1.800 \pm .300$ & $1.533 \pm .252$ & $91.667 \pm 2.517$ \\
HPMC 20.6mg/unit & $97.667 \pm 1.528^{*}$ & $0.650 \pm 0.118^{* *}$ & $2.10 \pm .265^{* * *}$ & $99.10 \pm 1.153^{*}$ \\
\hline
\end{tabular}

${ }^{*} P<0.050$ compared with other batches of HPMC and $P V P K 30$.

${ }^{* *} P<0.050$ compared with $P V P K 30$

${ }^{* * *}$ significant difference compared with $10 \mathrm{mg} H P M C$ and PVP K 30. \# P<0.001 compared 10 and $20 \mathrm{mg}$ of PVP K 30 and HPMC.

$\# \# P<0.05$ compared with PVP K 30 and $10 \mathrm{mg}$ of HPMC $(P<0.001)$

Table 4: Effect of talc on Dissolution and Pellet nature.

\begin{tabular}{ccc}
$\begin{array}{c}\text { Formulation } \\
\text { Variable }\end{array}$ & $\begin{array}{c}\text { Amount of Multi pellets } \\
(\%)\end{array}$ & $\begin{array}{c}\text { Dissolution at } 10^{\text {th }} \text { min } \\
(\%)\end{array}$ \\
\hline Without Talc & $12.33 \pm 3.05$ & $35.667 \pm 2.082$ \\
Talc $10 \mathrm{mg}$ & $7 \pm 2.00$ & $32.000 \pm 2.000$ \\
Talc $15 \mathrm{mg}$ & $2 \pm 3.667^{*}$ & $29.333 \pm 1.528$ \\
Talc $20 \mathrm{mg}$ & $5.20 \pm 5.067^{*}$ & $21.833 \pm 1.607^{*}$ \\
\hline
\end{tabular}

${ }^{*}$ Highly significant compared without talc

$(\mathrm{P}<0.001)$, whereas no significant difference, when compared with 10 and $20 \mathrm{mg}$ of HPMC. $20.6 \mathrm{mg}$ of HPMC significantly increased the disintegration time compared with $10 \mathrm{mg}$ of $\mathrm{HPMC}(\mathrm{P}<0.001)$ and $10 \mathrm{mg}$ PVP K $30(\mathrm{P}=0.006)$. However, no significant difference in comparison with $20 \mathrm{mg}$ of PVP K 30 and HPMC. Compared with PVP K 30 and HPMC $20 \mathrm{mg}, 20.6 \mathrm{mg}$ HPMC does not have a significant difference in disintegration time. The assay values for pellets made with $20.6 \mathrm{mg} \mathrm{HPMC}$ have increased significantly when compared with 10 and $20 \mathrm{mg}$ of PVP K $30(P=0.006, P<0.050)$ and HPMC $(P<0.001, P<0.008)$ respectively. The rate of dissolution also increased in comparison with 10 and $20 \mathrm{mg}$ of PVP K $30(P<0.050)$ and 10mg of HPMC $(P<0.001)$.

\section{Optimization of Talc}

Development of pellets in FBP generates free energy which attracts the pellets each other resulting in the formation of the multi pellet. Talc is added as an anti-static agent in drug loading dispersion to neutralize the surface charge and reduce the cohesive force among the pellets. The optimum level of talc was determined based on the formation of the least amount of multi pellets and better dissolution. The evaluation test results for the optimization of talc in the drug layer are given in Table $4.15 \mathrm{mg}$ of talc reduced the amount of multi pellets and improved the process feasibility. Due to the hydrophobic nature of talc, an excess amount reduces the dissolution. Compared with the drug-loaded pellets without talc, $15 \mathrm{mg}$ and $20 \mathrm{mg}$ of talc in drug dispersion significantly reduce the amount of multi pellet formed $(P=0.004, P=0.011)$ and the dissolution $(P=0.012, P<0.001)$ respectively.

\section{Optimization of Disintegrant}

An initial rapid dissolution is necessary for a delayed-release product to give better bioavailability. From the dissolution studies conducted, it was observed that the addition of talc reduced the initial dissolution rate. To achieve this, a varying amount of corn starch as a disintegrate was tested and optimized based on dissolution at 10th min the results. Table 5 shows the percentage dissolution after the addition of corn starch in the drug layer. No proportionality in dissolution concerning the concentration of corn starch was observed.
Table 5: Effect of Disintegrant on dissolution.

\begin{tabular}{cccc}
\hline \multirow{2}{*}{ Formulation } & \multicolumn{3}{c}{ Dissolution \% } \\
\cline { 2 - 4 } & $10 \mathrm{~min}$ & $20 \mathrm{~min}$ & $30 \mathrm{~min}$ \\
\hline With Out Corn Starch & $35.667 \pm 2.082$ & $71.400 \pm 4.276$ & $95.833 \pm 2.363$ \\
Corn Starch 10 & $40.767 \pm 3.027^{*}$ & $73.93 \pm 3.900$ & $96.033 \pm 1.050$ \\
Corn Starch 15 & $53.067 \pm 2.723^{*}$ & $77.400 \pm 2.163$ & $96.500 \pm 1.803$ \\
Corn Starch 20 & $63.133 \pm 4.456^{*}$ & $77.733 \pm 2.053$ & $95.467 \pm 1.747$ \\
\hline
\end{tabular}

${ }^{*}$ significantly increased the dissolution compared without corn-starch

Table 6: Results for optimization of barrier coating.

\begin{tabular}{|c|c|c|c|c|c|c|c|}
\hline \multirow{3}{*}{ Formula } & \multicolumn{4}{|c|}{ Water by KF } & \multirow{3}{*}{ 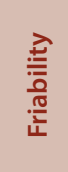 } & \multirow{3}{*}{ 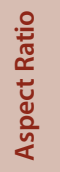 } & \multirow{3}{*}{ 흐응 } \\
\hline & \multirow{2}{*}{ 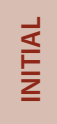 } & \multicolumn{3}{|c|}{$40 \pm 2^{\circ} \mathrm{C} / 75 \pm 5 \% \mathrm{RH}$} & & & \\
\hline & & $\begin{array}{c}5 \\
\text { DAYS }\end{array}$ & $\begin{array}{c}10 \\
\text { DAYS }\end{array}$ & $\begin{array}{c}15 \\
\text { DAYS }\end{array}$ & & & \\
\hline $\begin{array}{l}\text { Sucrose, } \\
\text { talc, HPMC } \\
(45: 25: 30),\end{array}$ & 2.3 & 4.5 & 5.2 & 6.7 & 1.5 & 1.2 & $\begin{array}{l}\text { light } \\
\text { pink }\end{array}$ \\
\hline $\begin{array}{l}\text { HPMC and } \\
\text { Talc }(75: 25)\end{array}$ & 2.4 & 3.2 & 3.9 & 5.6 & 0.75 & 1.2 & white \\
\hline $\begin{array}{c}\text { Povidone K } \\
30 \text { and Talc } \\
(75: 25)\end{array}$ & 2.6 & 3.5 & 4.5 & 5.2 & 0.9 & 1 & white \\
\hline $\begin{array}{l}\text { Opadry }^{\circ} \mathrm{AMB} \\
\text { white }\end{array}$ & 2.6 & 3.3 & 3.4 & $3.8^{*}$ & 0.8 & 1.1 & white \\
\hline
\end{tabular}

"Significantly less moisture content compared with other barrier coating $(P<0.001)$

At $20^{\text {th }}$ and $30^{\text {th }}$ min no significant difference in dissolution compared with the batch without cornstarch was seen $(P>0.050)$. At $10^{\text {th }} \mathrm{min}, 10 \mathrm{mg}$ $(P=0.029), 15$ and $20 \mathrm{mg}(P<0.001)$ cornstarch has significantly increased the dissolution compared with the pellets without corn starch. No significant difference in dissolution was observed for $15 \mathrm{mg}$ compared with $20 \mathrm{mg}$. Thus based on the statistical significance $15 \mathrm{mg}$ of corn starch was optimized as a disintegrant in the drug layer.

\section{Stage 2: Barrier coated pellets}

To prevent the drug enteric polymer interaction, the barrier coating is necessary for delayed-release DDS. The barrier material must be compatible with the drug and it should not permeate the moisture. The polymers for barrier layer is selected based on moisture uptake, Friability, Aspect ratio and Color of the pellets after stability study at $40 \pm 2^{\circ} \mathrm{C} / 75 \pm 5 \% \mathrm{RH}$ in an open condition for 3 days. The results are given in Table 6. The major principle involved in this concept is that permeable 
Suseem and Joseph.: Development of Duloxetine $\mathrm{HCl}$ delayed-release Capsules

Table 7: Effect of Enteric Coating Build Up With Eudragit L-100-55 and L-30-D-55 on Dissolution.

\begin{tabular}{|c|c|c|c|c|c|c|c|}
\hline Time (min) & $15 \%$ L-100-55 & $20 \%$ L-100-55 & $25 \%$ L- $100-55$ & $15 \%$ L-30-D-55 & $20 \%$ L-30-D-55 & $25 \%$ L-30-D-55 & $30 \%$ L-30-D-55 \\
\hline \multicolumn{8}{|c|}{ Acid stage Drug Release } \\
\hline 120 & $4.7 \pm 0.45$ & $1.23 \pm 0.45$ & $0 \pm 0^{*}$ & $24.46 \pm 3.30$ & $4.06 \pm 0.90$ & $0.56 \pm 0.60^{*}$ & $0 \pm 0^{*}$ \\
\hline \multicolumn{8}{|c|}{ Drug release in $\mathrm{pH} 6.8$ phosphate buffer } \\
\hline 135 & $70.6 \pm 2.38$ & $71.8 \pm 4.233$ & $11.33 \pm 4.04$ & $65.66 \pm 1.40$ & $70.2 \pm 3.25$ & $43.00 \pm 1.00^{*}$ & $25.66 \pm 2.08^{\sharp}$ \\
\hline 150 & $80.86 \pm 3.38$ & $82.4 \pm 3.85$ & $38.73 \pm 3.75$ & $68.86 \pm 3.82$ & $73.93 \pm 4.56$ & $74.33 \pm 2.51^{\#}$ & $64.66 \pm 2.08^{\sharp}$ \\
\hline 165 & $80.9 \pm 2.13$ & $92.13 \pm 2.80$ & $55.0 \pm 2.72$ & $71.7 \pm 2.47$ & $75.56 \pm 1.00$ & $87.5 \pm 2.3^{\# @ ~}$ & $81.23 \pm 2.51^{*}$ \\
\hline 180 & $87.33 \pm 2.08$ & $92.13 \pm 2.38$ & $63.23 \pm 3.85$ & $73.6 \pm 1.90$ & $81.06 \pm 2.96$ & $88.36 \pm 3.75^{* ®}$ & $86.93 \pm 2.66^{\#}$ \\
\hline 210 & $89.36 \pm 2.20$ & $92.8 \pm 1.40$ & $74.46 \pm 2.84$ & $72.86 \pm 2.05$ & $88.66 \pm 2.96$ & $93.2 \pm 0.85^{\# @ ~}$ & $87.3 \pm 1.01^{\#}$ \\
\hline
\end{tabular}

"No statistical significant difference between 25\% L-100-55, 25\% L-30-D-55 and 30\% L-30-D-55 ( $P>0.050)$.

\# statistically significantly and superior $(P<0.001)$ drug release compared with $25 \% \mathrm{~L}-100-55$ at all dissolution time points.

${ }^{\circledR}$ statistically significant and superior $(P<0.001)$ in drug release compared with $30 \% \mathrm{~L}-30-\mathrm{D}-55$

barrier layers can uptake moisture along with free acid moiety of the enteric layer to interact with the drug resulting in instability of the product. Pink or dark color pellets is the visual identification method for this interaction. Thus, in this study, a suitable polymer as a barrier material is evaluated and optimized. Combination of sucrose, HPMC and talc is highly permeable to moisture, still different studies conducted with this combination as a barrier layer with ratios of 80:10:10 to 20:70:10 and tested for its drug release. Among the various polymers tested for moisture permeability and product stability, O-AMB is more suitable to keep the product more stable. At 15thday, the moisture content fO-AMB white is very statistically less $(P<0.001)$ compared with other barriers. Opadry ${ }^{\oplus}$ AMB consists of partially hydrolyzed PVA, Titanium dioxide, talc, lecithin, soya and xanthan gum.

\section{Stage 3: Enteric-coated pellets}

The level of plasticizer in the coating solution and thickness of enteric polymer is optimized based on the acid resistance of the film and drug release in a buffer medium. Plasticizer has a vital role in the formation of arate controlling membrane. It interacts with the polymer chain to form a flexible, smooth and shock-resistant membrane. ${ }^{15}$ Tri ethyl citrate is the plasticizer of choice for Eudragit L $30-\mathrm{D}-55^{16}$ because of its aqueous solubility and Triacetin is the proven choice for Eudragit L 100-55. ${ }^{13}$ Based on the preliminary studies (acid release) on plasticizer, a concentration of $10 \%$ is optimized. The barrier coated pellets were coated with hydroalcoholic dispersion of Eudragit L 100-55 along with talc as an anti-static agent at a varying coating thickness of 15\%,20\%, $25 \%$ and an aqueous dispersion of Eudragit L 30-D-55 at a varying coating thickness of $15 \%, 20 \%, 25 \%$ and $30 \%$. Eudragit L 10055 is an anionic copolymer based on methacrylic acid and ethyl acrylate. Whereas Eudragit L 30 D 55 is the aqueous dispersion of anionic polymers with methacrylic acid, as a functional group. ${ }^{13}$ The pellets were evaluated based on acid resistance in $0.1 \mathrm{M} \mathrm{HCl}$ and dissolution at $\mathrm{pH} 6.8$ phosphate buffer the results shown in Table 7 . The pellets with $15 \%$ and $20 \%$ thickness of both the polymers failed in acid resistance. A25\%L100-55 and30\%L30-D-55 is highlyacid-resistant but the initial drug release in the buffer stage is very less compared with 25\% L30-D-55.

$25 \%$ of Eudragit L 100-55 maintains an acid resistance; however, upto $30 \%$ polymer weight gain is required for Eudragit L $30-\mathrm{D}-55$ to attain the $0 \%$ acid release. The acid release must not be greater than 3\%. $20 \%$ weight gain of Eudragit L 100-55 produce an acid release of $1.2 \%$ which is very marginal. Any irregularity in the enteric coating can boost the acid release. However, $25 \%$ of polymer build-up declined the acid stage and buffer stage drug release. For an enteric-coated DDS, an immediate drug release in the buffer stage is essential for better bioavailability. This
Table 8: Effect of Top Coating on Moisture Permeation.

\begin{tabular}{cc}
\hline Formulation & $\%$ Moisture content \\
\hline Pellets Without top coating & $4.2 \pm 0.551$ \\
Pellets coated with 5\%O-AMB & $2.8 \pm 0.503$ \\
Pellets coated with 10\%O-AMB & $2.7 \pm 0.351$ \\
\hline
\end{tabular}

* Significant difference in comparison with pellets without top coating

demonstrates that the Eudragit L 10055 coating is highly rigid and hold more time to dissolve. ${ }^{17} 25-30 \%$ of Eudragit L $30-\mathrm{D}-55$ is essential to arrest the acid stage drug release. As the percentage polymer weight gain increases, the drug release retards. A proportional reduction in drug release was observed with increased polymer thickness. Even though $30 \%$ of Eudragit L30-D-55 produced no acid release, the buffer stage drug release was hampered

\section{Stage 4: Top coated pellets}

Compared with the enteric-coated pellets without top coating, the pellets coated with $5 \%$ and $10 \% \mathrm{O}-\mathrm{AMB}$ showed less moisture content even after 15 days direct exposure to $40 \pm 2^{\circ} \mathrm{C} / 75 \pm 5 \% \mathrm{RH}(P<0.050)$ as listed in Table 8. No significant difference in moisture content $(P=0.587)$ between $5 \%$ and $10 \%$ coated pellets. Thus, $5 \%$ with $\mathrm{O}-\mathrm{AMB}$ is enough to act as a moisture barrier without affecting dissolution.

\section{Statistical comparison with Cymbalta ${ }^{\circledR}$}

The developed formula and process is further validated and the results were compared with marketed formulation Cymbalta ${ }^{\oplus}$. Figure 3, explains the dissolution comparison with the marketed formulation. Statistically no significant difference $(P=0.427)$ in acid stage drug release. But In the buffer stage, the dissolution rate was faster than the standard. The similarity factor $f_{2}$ was determined. Table 9 shows the $f_{2}$ values at each time point. The $f_{2}$ values are within the limit of 50-100. The similarity between the developed formulation and marketed preparation was found to be $66.29 \%$ and f1differential factor was found to be $6.50 \%$. Other evaluation tests on the developed product were conducted and compared with the standard, drug content is $99.767 \pm 1.353 \%(P=0.319)$, Initial Moisture content $2.267 \pm 0.321 \%(P=0.781)$, Moisture content after 15 days stability study $2.80 \pm 0.300 \%(\mathrm{P}=0.249)$ the pellet nature was pure spherical without colour change. Gastric challenge $99.133 \pm 0.833 \%$ $(P>0.790)$. Suggest the developed formulation suitable for in-vivo bioequivalence studies. 
Table 9: Similarity factor in comparison with marketed formulation Cymbalta ${ }^{\oplus}$.

\begin{tabular}{cc}
\hline Time $(\min )$ & F2 \\
\hline 120 & 94.30 \\
135 & 67.52 \\
150 & 68.78 \\
165 & 53.02 \\
180 & 64.33 \\
210 & 89.04 \\
Overall & 66.29 \\
\hline
\end{tabular}

\section{DISCUSSION}

According to BCS classification, DXL classified as Class II with low solubility. ${ }^{18}$ Thus, for better bioavailability, the solubility of DXL must be improved. HPMC also act as a solubility enhancer. It improved the solubility of various class II drugs in molecular dispersion. A lower concentration of PVP and HPMC reduces the dissolution whereas a higher concentration increases the solubility proportionally. ${ }^{19}$ HPMC changes the physical nature of API to amorphous form and reduces drug precipitation. ${ }^{20} \mathrm{HPMC}$ has many hydroxyl groups; this group may accept or donate hydrogen bond resulting in enhanced drug solubility. ${ }^{21}$ In contrary to the above an excess concentration of PVP reduces the dissolution. ${ }^{22}$ Based on the above findings $20.6 \mathrm{mg}$ of HPMC is optimized as the suitable binder for the drug layer.

Talc is highly recommended as an anti-tacking agent in the film-forming coating to prevent the agglomeration. Talc is more preferred with aqueous-based coating system than non-aqueous coating. ${ }^{23}$ It also has the film thickening property. The use of $10 \% \mathrm{w} / \mathrm{w}$ talc in coating solution retards the drug release from the coated pellets compared with non-talc pellets. The strong hydrophobic nature of talc prevents the drug to diffuse through the coating film. ${ }^{24}$ Thus based on the least multi pellet count, $15 \mathrm{mg}$ talc is optimized.

The varying concentration of sucrose and HPMC changes the drug release but it doesn't retard the drug release. ${ }^{8}$ Presence of sucrose in the barrier layer increases the acidresistance. ${ }^{25}$ HPMC, talc Combination and PVP K 30, talc Combination as barrier reduced the moisture permeability, but the moisture content is higher than the predictable limit. 10\% HPMC as a physical barrier reduces the impurity formation in pellets, ${ }^{26}$ permeation of drug across the barrier during storage and improves the stability at $40 \pm 2^{\circ} \mathrm{C} / 75 \pm 5 \% \mathrm{RH} .{ }^{27} \mathrm{PVP} \mathrm{K} 30$ produces high mechanical strength to core pellets with a friability $<1 \%$ along with glass spheres. The aspect ratio report to be $1.11 \pm 0.06^{12}$ which is similar in comparison to the developed product.

The studies on $\mathrm{O}-\mathrm{AMB}$ indicate a reduction in moisture uptake on increasing the coating thickness from $0 \%-5 \%$ and no moisture uptake at $20 \%$ coating. ${ }^{28}$ Compared with other moisture barriers O-AMB is highly impermeable, due to its partially hydrolyzed PVA. The amorphous form of polymers is more permeable than crystalline forms. The glass transition temperature of polymer also affects the permeability and stability. ${ }^{29}$ The glass transition temperature decreases with increase in moisture uptake. Thus, the moisture that permeates through the barrier also influences the glass transition temperature. In presence of moisture, the polymer in $\mathrm{O}-\mathrm{AMB}$ converts from glassy state to rubbery state. Thus, the water uptake capacity of O-AMB increases with increase in temperature. ${ }^{30}$ The pigments present in the $\mathrm{O}-\mathrm{AMB}$ also have a wide role in moisture permeability.
The presence of intermolecular space in the polymer film is closed by the insoluble pigments, this makes the polymer film more impermeable. This also depends on the concentration of pigments. Above a particular concentration, the pigments also act as pore-forming agents, which facilitates the movement of moisture across the barrier. The polyhydric materials in the polymer film, form hydrogen bonds with the water molecule and reduce the possibility of the water molecule to reach the core of pellets. ${ }^{31}$ Based on the above discussion $\mathrm{O}-\mathrm{AMB}$ is finalized as the barrier coating polymer.

Eudragit L 30-D-55 is more rubbery and elastic, which consumes more time for erosion. The extent of dissolution depends on the degree of ionisation of polymer. ${ }^{32}$ Once the enteric polymer dissolves, it immediately releases the drug. The polymer dissolution involves the process of water absorption, swelling and disentanglement. ${ }^{33}$ Thus, the greater the thickness of polymer more the duration for dissolution of the polymer. The process with Eudragit L-100-55 non-aqueous suspension found to be critical due to higher generation of fines and consumption of huge quantity of organic solvent which is hazardous. Thus based on the drug release profile and considering the safety aspects $25 \%$ enteric coating with Eudragit L $30-\mathrm{D}-55$ is found to be optimum. The two-way analysis of variance shows, no significant difference in drug release at the acid stage between the batches with 25\% L-100-55, 25\%L-30-D-55 and 30\% L-30-D-55 $(P>0.050)$, whereas in the buffer stage significant difference between the above three batches $(P<0.001)$ exist. Thus, by considering the least drug release in the acid stage and superior release in the buffer stage, $25 \%$ L-30-D-55 is optimized.

\section{CONCLUSION}

DXL is developed as Multiparticulate, gastro-resistant capsules since it is acid labile. Multiparticulate formulations have enormous advantages overall other oral dosage forms, especially in modified release formulation. The formulation is developed in a fluid is edbed processor (Wurster process), using the bottom spray. The final formula for DXL gastro-resistant capsules is developed by optimizing each excipient and its concentration in every stage of development in an evolutionary method. Based on results of the final batch, it is concluded that the formula is reproducible. The core spherical sugar spheres facilitate uniform functional coating. The developed product is less permeable to moisture and the Barrier layer fully protects the drug from interaction with enteric polymer. Use of talc improved the process efficiency. The top coating arrests the moisture permeability during storage and provides a rich finishing to the product. The product is highly acid-resistant and has good dissolution profile in $\mathrm{pH} 6.8$ phosphate buffer, compared with the marketed formulation. The statistical comparison and similarity factor $\mathrm{f} 2$ confirm the similarity of the developed product with marketed product Cymbalta ${ }^{\circledR}$. As the product is pharmaceutically equivalent to the marketed formulation, it is recommended for in-vivo bioequivalence studies.

\section{ACKNOWLEDGEMENT}

We thank Orchid health Care, Chennai for providing the full support for conducting the research and Dr. Manju Mariya Mathews, Professor, Nirmala College of Pharmacy, Muvattupuzha for providing the writing assistance and proofreading.

\section{CONFLICT OF INTEREST}

The authors declare no conflict of interest.

\section{ABBREVIATIONS}

MDD: Major depressive disorder; SNRIs: Serotonin and noradrenaline reuptake inhibitors; EMEA: European Medicinal Agency ; DXL: Dulox- 
etine hydrochloride; MPDDS: Multi-particulate drug delivery systems; FBP: Fluidized bed processor; O-AMB: Opadry ${ }^{\circledR}$ AMB; TEC: Triethyl citrate.

\section{REFERENCES}

1. Schmaal L, Veltman DJ, Erp TGV, Smann PG, Frodl T, Jahanshad N, et al Subcortical brain alterations in major depressive disorder: Findings from the enigma Major Depressive Disorder working group. Mol Psychiatry. 2016;21(6):806-12

2. Gerber M, HolsboerTE, Phse U, Brand S. Exercise is medicine for patients with major depressive disorders: But only if the pill is taken. Neuropsychiatr Dis Treat. 2016;12:1977-81.

3. Otte C, Gold SM, Penninx BW, Pariante CM, Etkin A, Fava M, et al. Major depressive disorder. Nat Rev Dis Primers. 2016;2:16065.

4. Tripady KD. Essentials of Medical Pharmacology. Drugs acting on central Nervous System. 2013;462-3.

5. Mcintyre RS, Panjwani ZD, Nguyen HT, Woldeyohannes HO, Alsuwaidan M, Soczynska JK, et al. The hepatic safety profile of duloxetine: A review. Expert Opin Drug Metab Toxicol. 2008;4(3):281-6.

6. Gandhi B, Baheti J. Multiparticulates drug delivery systems: A review. Int J Pharm Chem Sci.2013;2(3):1620-6.

7. Dey NS, Majumdar S, Rao ME. Multiparticulate drug delivery systems for controlled release. Trop J Pharm Res. 2008;7(3):1067-75.

8. Roy SB, Kulkarni SK, Panchal MK, Shah KY. Inventors. Cadila Healthcare Ltd, assignee Pharmaceutical compositions for reducing alcohol-induced dose dumping United States patent application US 13/393,658.2012.

9. Jansen PJ, Oren PL, Kemp CA, Maple SR, Baertschi SW. Characterization of impurities formed by interaction of duloxetine $\mathrm{HCl}$ with enteric polymers hydroxyl propyl methyl cellulose acetatesuccin ate and hydroxyl propyl methylcellulose phthalate. Journal of Pharmaceutical Sciences. 1998:87(1):81-6.

10. Visanko M, Liimatainen $H$, Sirvi JA, Haapala A, Sliz R, Niinimki J, et al. Porous thin film barrier layers from 2,3-dicarboxylic acid cellulose nano fibrils for membrane structures. Carbohydr Polym. 2014;102:584-93.

11. Heinmki K, Vesalahti J, Marvola J, Antikainen M, Yliruusi OJ. Extrusionspheronization of $\mathrm{pH}$-sensitive polymeric matrix pellets for possible colonic drug delivery. Int J Pharm. 2000;199(2):187-94

12. Shivakumar HN, Suresh S, Desai BG. Design and evaluation of $\mathrm{pH}$ sensitive multi-particulate systems for chronotherapeutic delivery of diltiazem hydrochloride. J Pharm Sci. 2006;68(6):781.

13. Gutirrez-Rocca J, Mcginity JW. Influence of water soluble and insoluble plasticizers on the physical and mechanical properties of acrylic resin copolymers. Int J Pharm. 1994;103(3):293-301.

14. Bando H, Mcginity JW. Physicochemical properties of enteric films prepared from aqueous dispersions and organic solutions. Int J Pharm. 2006;313(1-2):43-8.

15. Vyas VU, Nagesh N, Mittapalli PK. Pharmaceutical formulation comprising duloxetine. US Patent US 20090226517A1. 2006.

16. Khatri $P$, Desai $D$, Shelke N, Minko T. Role of plasticizer in membrane coated extended release oral drug delivery system. J Drug Deliv Sci Technol. 2018;44:231-74.

17. Sauer D, Watts AB, Coots LB, Zheng WC, Mcginity JW. Influence of polymeric sub coats on the drug release properties of tablets powder-coated with pre-plasticized Eudragit L 100-55. Int J Pharm. 2009;367(1-2):20-8.

18. Rowe RC, Sheskey PJ, Quinn M. Handbook of pharmaceutical excipients 2013;18:544.

19. Park S, Kang Z, Thapa P, Jin Y, Park J, Lim H, et al. Development of sorafenib loaded nanoparticles to improve oral bioavailability using a quality by design approach. Int J Pharm. 2019;566:229-38.

20. Ha ES, Choo GH, Baek IH, Kim MS. Formulation, characterization and in vivo evaluation of celecoxib- PVP solid dispersion nanoparticles using supercritical anti solvent process. Molecules. 2014;19(12):20325-39.

21. Choi JY, Yoo JY, Kwak HS, Nam BU, Lee J. Role of polymeric stabilizers for drug nano crystal dispersions. Curr Appl Phys. 2005;5(5):472-4.

22. Homayouni A, Nokhodchi A, Sadeghi F, Varshosaz J, Garekani H. Comparing various techniques to produce micro/nanoparticles for enhancing the dissolution of celecoxib containing PVP. Eur J Pharm Biopharm. 2014;88(1):261-74.

23. El-Malah Y, Nazzal S. Effect of Eudragit RS 30D and talc powder on verapamil hydrochloride release from beads coated with drug layered matrices. AAPS Pharm Sci Tech. 2008;9(1):75-83.

24. Hu LD, Liu Y, Tang X, Zhang Q. Preparation and in vitrolin vivo evaluation of sustained-release met- for min hydrochloride pellets. Eur J Pharm Biopharm. 2006;64(2):185-92.

25. Kuang C, Sun Y, Li B, Fan R, Zhang J, Yao Y, et al. Preparation and evaluation of duloxetine hydrochloride enteric-coated pellets with different enteric polymers. Asian J Pharm Sci. 2017;12(3):216-42.

26. Jansen PJ, Oren PL, Kemp CA, Maple SR, Baertschi SW. Characterization of impurities formed by interaction of duloxetine $\mathrm{HCl}$ with enteric polymers hydroxy propyl methyl cellulose acetate succinate and hydrox ypropyl methylcellulose phthalate. Journal of Pharmaceutical Sciences. 1998;87(1):81-6.

27. Krber M, Hoffart V, Walther M, Macrae RJ, Bodmeier R. Effect of un conventional curing conditions and storage on pellets coated with Aquacoat ECD. Drug Dev Ind Pharm. 2010;36(2):190-9.

28. Bley O, Siepmann J, Bodmeier R. Protection of moisture-sensitive drugs with aqueous polymer coatings: Importance of coating and curing conditions. Int J Pharm. 2009:378(1-2):59-65.

29. Lu Q, Zografi G. Properties of citric acid at the glass transition. Journal of Pharmaceutical Sciences. 1997;86(12):1374-82.

30. Bley O, Siepmann J, Bodmeier R. Importance of glassy-to-rubbery state transitions in moisture-protective polymer coatings. Eur J Pharm Biopharm 2009;73(1):146-53.

31. Porter SC. The effect of additives on the properties of an aqueous film coating Pharm Technol. 1980; 4(3):66.

32. Shravani D, Lakshmi PK, Balasubramaniam J. Preparation and optimization of various parameters of enteric coated pellets using the Taguchi L9 orthogonal array design and their characterization. Acta Pharmaceutica Sinica B. 2011;1(1):56-63.

33. Shen X, Yu D, Zhu L, Branford-White C, White K, Chatterton NP. Electros pundiclofenac sodium loaded Eudragit L 100-55 nanofibers for colon-targeted drug delivery. Int J Pharm. 2011;408(1-2):200-7.

Article History: Submission Date : 19-03-2020; Revised Date : 20-04-2020; Acceptance Date : 02-05-2020

Cite this article: Suseem SR, Joseph D. Formulation Development and Evaluation of Duloxetine Hydrochloride Multi-Particulate Delayed-Release Capsules. Int. J. Pharm. Investigation. 2020;10(2):160-6. 